\title{
Recommendations For The Management Of Patients With Depression In General Clinical Practice
}

\author{
Zoryana Lebedyn
}

\begin{abstract}
Depression is one of the biggest health problems. If patient has symptoms of depression, then the patient should be treated. Patients with depression have a four times higher risk of suicide than the general population, which worsens their physical health and overall quality of life. This is associated with an increased risk of coronary heart disease, stroke, pain, alcohol abuse, smoking and illicit drug use. This determines the urgency of the problem of depression at the stage of primary care. A good family-patient relationship is essential in the treatment of depressed patients. In the practice of a general practitioner the prevalence of depression is 5\%. Each year, two patients are hospitalized for depression, and one patient commits suicide every other day. The formation of the patient's attitude to the disorder depends on the correct assessment by doctor. There is a need for a clear ability to use various depression screening tools be general practitioners. This article discusses some available recommendations for depression management for primary health care physicians.
\end{abstract}

Index Terms - depression, antidepressants, major depressive disorder, general practitioner, bipolar disorder, daily living activities

\section{INTRODUCTION}

Depression is one of the leading causes of disability worldwide [1], [2], [3]. Primary care professionals are usually the first to come into contact with such patients, so they should be aware of the diagnosis and further treatment of these individuals. This is a review article of some available sources, including American Psychiatric Association (APA) and Institute for Clinical Systems Improvement (ICSI) guidelines for the management of patients with depression, adapted by a working group from the University of Wisconsin. The recommendations and guidelines are aimed at primary care physician to optimize disorder detection, prioritize interventions, evaluate their effectiveness and efficiency, or refer them to specialized clinics.

\section{IDENTIFICATION OF PATIENTS WITH DEPRESSION}

Complaints of deteriorating physical health are extremely common among patients with depression and is mostly the main manifestation of the disorder. It is equally important to identify the somatic manifestations of depression, as well as biological, psychological and environmental risk factors [1].

The US Preventive Services Working Group (USPSTF) recommends screening for depressive symptoms in the first place [4]. The initial examination of the patient should include the use Patient Health Questionnaire (PHQ-2) at each current visit, as well as under the time of the annual preventive medical assessment and if this has not been done during the previous 90 days. When receiving results for PHQ$2 \geq 3$ then patient should be screened with a full version of the PHQ-9 questionnaire. In case of receiving a PHQ-9 of $\geq 10$, it is necessary to conduct a full and comprehensive clinical assessment.

\section{DIAGNOSTIC PROCEDURE}

The first step is to check for symptoms to meet the criteria for depressive disorder according to the Diagnostic and Statistical Manual of Mental Disorders (DSM-5) [1], [2], [3]. Comorbid psychiatric disorders and other medical conditions should also be identified and the patient's functional status assessed [5], [6], [7], [8]. When making a differential diagnosis, clinicians should keep in mind that many other mental disorders, somatic conditions, or even the use of certain medications can cause symptoms of depression [9], [10], [11], [12]. Therefore, when assessing the patient's condition, the primary care physician should clearly determine whether depression is the initial stage of this process or a symptom of other disease or disorder.

\section{PRINCIPLES OF TREATMENT}

The use of psychotherapy, pharmacotherapy or both interventions should be based on the severity of the symptoms of depression, the presence of comorbidities, financial capabilities of the patient.

During the acute phase that lasts 6-12 weeks, contact with the patient (by phone or in person) one week after diagnosis and treatment, and then every 2 to 4 weeks before remission or response to treatment until the remission. The mild form of depression corresponds to 5-9 points on the PHQ-9 scale. In mild cases only psychotherapy and / or behavioral activation techniques should be recommended [13].

Moderate depression corresponds to 10-19 points on PHQ9. In this case, psychotherapy (Cognitive behavioral therapy (CBT) or Interpersonal psychotherapy (IPT)), pharmacotherapy, or combination therapy (combination of medication and psychotherapy) [14].

Severe depression corresponds to 20-27 points for PHQ-9. Pharmacotherapy or combination therapy or electroconvulsive therapy (ECT) are recommended in this case [1], [2], [3], [7], [8], [14].

General practitioner should consider referring the patient 
to a specialist in case of risk of bipolar disorder development or onset, psychiatric comorbidity (use of psychoactive substances, anxiety, OCD, eating disorders), risk of suicide and / or murder, symptoms of psychosis, insufficient effectiveness of their drugs, significant or prolonged disability, inability to care for themselves and / or family and diagnostic uncertainty [1], [4], [5], [9], [10], [11], [14], [15].

The initial response to PHQ-9 therapy should be evaluated after 4-6 weeks of pharmacotherapy (monotherapy or combination therapy), or after 6-12 weeks of psychotherapeutic interventions in the form of monotherapy. In case of poor or no respond to the treatment, correction or change of therapy should be done step by step. Adherence to therapy should be assessed, the dosage of the drug should be carefully adjusted, the number of psychotherapeutic sessions should be increased, treatment should be intensified or changed, and finally the patient should be referred to a specialist. Assess response to the treatment with PHQ-9 at 4 to 8 weeks after treatment change [14], [15].

During this period, the phase of continuation of treatment occurs, which should last 4-9 months. Contact with the patient by phone or in person every 1-3 months.

At the end the phase of maintenance treatment comes that lasts 1 year. At this stage, treatment should be stopped and antidepressant therapy should be stopped within a few weeks and the patient should be informed about the cessation of psychotherapeutic interventions. End therapy and maintain contact with the patient every 3-12 months in case of stabilization is advised [1], [2], [3], [13], [14].

When choosing a particular drug, it is necessary to take into account comorbid disorders (Table 1. Treatment of depression with comorbid conditions) and possible side effects (Table 2. Possible side effects), co-prescribed drug therapy and economic costs [1], [13], [14], [16], [17]. All patients with depression in the primary care system should be included in a register of family doctor or general practitioner in which the psychiatrist with the collaboration of care manager actively monitors changes in the patient's symptoms and promotes adherence to the treatment plan.

Depression increases the risk of dental and gum disease [18], [19]. The fact is that cortisol, coupled with psychological stress, negatively affects the bone tissue of the oral cavity. And if a person is prone to prolonged depression, he may even completely lose his teeth. A particularly serious danger is the craving of a depressed person for sweets - with the help of chocolate, for example, the patient may try to raise the level of endomorphins. Regular visits to the dentist help protect teeth and will prevent caries to turn into pulpitis. Prevention of gum disease is equally important for people suffering from periodontitis, gingivitis, because due to the accumulation of plaque, inflammation of the soft tissues occurs.

TABLE I. TREATMENT OF DEPRESSION WITH COMORBID CONDITIONS

\begin{tabular}{|c|c|c|}
\hline Comorbid conditions & $\begin{array}{l}\text { First-line drugs } \\
\end{array}$ & Possible problems \\
\hline $\begin{array}{l}\text { Without comorbid } \\
\text { disorder }\end{array}$ & $\begin{array}{l}\text { Fluoxetine, citalopram, escitalopram, paroxetine, sertraline, } \\
\text { trazodone, mirtazapine, venlafaxine, desvenlafaxine, bupropion }\end{array}$ & $\begin{array}{l}\text { Side effect profile in the case of TCA most unfavorable, } \\
\text { nefazodone associated with hepatotoxicity }\end{array}$ \\
\hline $\begin{array}{l}\text { Excessive alcohol } \\
\text { consumption }\end{array}$ & & $\begin{array}{l}\text { Duloxetine is associated with liver damage, it increases bilirubin } \\
\text { level and may led to the development of obstruction }\end{array}$ \\
\hline Pregnancy & Sertraline, citalopram, fluoxetine, TCA & Paroxetine, venlafaxine, duloxetine \\
\hline $\begin{array}{l}\text { Anxiety and panic } \\
\text { disorder }\end{array}$ & $\begin{array}{l}\text { Paroxetine, fluoxetine, mirtazapine, sertraline, citalopram, } \\
\text { escitalopram, venlafaxine, desvenlafaxine }\end{array}$ & Bupropion can cause to increase anxiety \\
\hline $\begin{array}{l}\text { Obsessive-compulsive } \\
\text { disorder }\end{array}$ & Fluoxetine, citalopram, escitalopram, sertraline, paroxetine & \\
\hline Elderly patients & & Fluoxetine, paroxetine \\
\hline Decreased appetite & TCA, mirtazapine & Venlafaxine, desvenlafaxine, SSRIs \\
\hline Chronic pain & TCA, duloxetine & \\
\hline $\begin{array}{l}\text { Cardiovascular } \\
\text { pathology }\end{array}$ & Sertraline & $\begin{array}{l}\text { TCA, venlafaxine, desvenlafaxine, bupropion (increases arterial } \\
\text { blood pressure), mirtazapine (increases cholesterol level), } \\
\text { citalopram }\end{array}$ \\
\hline Diabetes & Fluoxetine, citalopram, escitalopram, paroxetine, sertraline & $\begin{array}{l}\text { TCA, mirtazapine (may occur desire to consume carbohydrates), } \\
\text { duloxetine (slows defecation stomach), paroxetine }\end{array}$ \\
\hline Dementia & Bupropion, mirtazapine, citalopram & \\
\hline Post-stroke dementia & Citalopram, escitalopram, sertraline & TCA, paroxetine, mirtazapine, bupropion \\
\hline Glaucoma & Fluoxetine, citalopram, escitalopram, sertraline, bupropion & TCA, paroxetine, duloxetine, venlafaxine, desvenlafaxine \\
\hline $\begin{array}{l}\text { Eating disorders } \\
\text { (anorexia, bulimia) }\end{array}$ & Fluoxetine, paroxetine, sertraline & Bupropion, mirtazapine \\
\hline Breastfeeding & Sertraline, Paroxetine & Fluoxetine \\
\hline Fibromyalgia & Duloxetine, venlafaxine & \\
\hline Liver disease & $\begin{array}{l}\text { Sertraline, venlafaxine (in low doses), desvenlafaxine (at low } \\
\text { doses) }\end{array}$ & $\begin{array}{l}\text { TCA, fluoxetine, paroxetine, citalopram, escitalopram, trazodone, } \\
\text { mirtazapine, nefazodone, duloxetine }\end{array}$ \\
\hline Epilepsy & Fluoxetine, citalopram, escitalopram, sertraline, paroxetine & $\begin{array}{l}\text { Bupropion, maprotiline, TCA (in the case of overdose), } \\
\text { duloxetine, venlafaxine, desvenlafaxine }\end{array}$ \\
\hline Pheochromocytoma & & Selegiline (patch) \\
\hline Parkinson's disease & $\begin{array}{l}\text { Bupropion, trazodone, desipramine, amoxapine, nortriptyline, } \\
\text { protriptyline }\end{array}$ & SSRIs, venlafaxine, desvenlafaxine, nefazodone, mirtazapine \\
\hline Kidney disease & Fluoxetine, citalopram, escitalopram, sertraline & $\begin{array}{l}\text { Mirtazapine, paroxetine, venlafaxine, desvenlafaxine, the level of } \\
\text { TCA is not prognostic }\end{array}$ \\
\hline $\begin{array}{l}\text { Symptoms: severe } \\
\text { sedation, weight gain, } \\
\text { lethargy }\end{array}$ & Bupropion, venlafaxine, desvenlafaxine & $\begin{array}{l}\text { Mirtazapine, TCA, trazodone, fluoxetine, sertraline, citalopram, } \\
\text { escitalopram, paroxetine }\end{array}$ \\
\hline $\begin{array}{l}\text { Symptoms: insomnia, } \\
\text { weight loss, increased } \\
\text { irritability }\end{array}$ & Mirtazapine, trazodone, TCA, paroxetine & Venlafaxine, desvenlafaxine, SSRIs, bupropion \\
\hline
\end{tabular}


TABLE II. POSSIBLE SIDE EFFECTS

\begin{tabular}{|c|c|c|}
\hline Symptoms & Drugs of the first line of therapy & Possible problems \\
\hline Agitation / insomnia & Mirtazapine, TCA & $\begin{array}{l}\text { Selegiline (patch), fluoxetine, sertraline, paroxetine, citalopram, } \\
\text { escitalopram, bupropion, venlafaxine, desvenlafaxine }\end{array}$ \\
\hline $\begin{array}{l}\text { Anticholinergic side effects (dry } \\
\text { mouth, blurred } \begin{array}{r}\text { vision, } \\
\text { constipation, } \\
\text { urinating) }\end{array}\end{array}$ & $\begin{array}{l}\text { Citalopram, escitalopram, fluoxetine, sertraline, } \\
\text { venlafaxine, desvenlafaxine, bupropion }\end{array}$ & TCA, paroxetine, mirtazapine, duloxetine, selegiline (patch) \\
\hline Hypersensitivity & Bupropion, TCA, mirtazapine & $\begin{array}{l}\text { Fluoxetine, sertraline, paroxetine, citalopram, escitalopram, } \\
\text { nefazodone, venlafaxine, desvenlafaxine, duloxetine }\end{array}$ \\
\hline Headache & TCA, mirtazapine & $\begin{array}{l}\text { Fluoxetine, sertraline, paroxetine, citalopram, escitalopram, } \\
\text { nefazodone, venlafaxine, desvenlafaxine, bupropion, selegiline (patch) }\end{array}$ \\
\hline Orthostatic hypotension & $\begin{array}{l}\text { Fluoxetine, sertraline, paroxetine, citalopram, } \\
\text { escitalopram, venlafaxine, desvenlafaxine, } \\
\text { bupropion }\end{array}$ & TCA, mirtazapine, trazodone, selegiline (plaster) \\
\hline Sedation & $\begin{array}{l}\text { Fluoxetine, sertraline, paroxetine, citalopram, } \\
\text { escitalopram, venlafaxine, desvenlafaxine, } \\
\text { bupropion }\end{array}$ & $\begin{array}{l}\text { TCA, nefazodone, trazodone, mirtazapine, selegiline (patch), } \\
\text { paroxetine }\end{array}$ \\
\hline Sexual dysfunction & Bupropion, mirtazapine & $\begin{array}{l}\text { Fluoxetine, sertraline, paroxetine, citalopram, escitalopram } \\
\text { nefazodone, venlafaxine, desvenlafaxine, bupropion, trazodone }\end{array}$ \\
\hline Weight gain & $\begin{array}{l}\text { Fluoxetine, sertraline, citalopram, escitalopram, } \\
\text { venlafaxine, desvenlafaxine, bupropion }\end{array}$ & TCA, paroxetine, mirtazapine, trazodone \\
\hline \multicolumn{3}{|c|}{ Features of use in the elderly (65 years and older) } \\
\hline Sleep disorders / insomnia & Mirtazapine & Benzodiazepines, paroxetine \\
\hline Weight loss & Mirtazapine & \\
\hline Anxiety & SSRI, SNRI & \\
\hline Drowsiness, decreased energy & Bupropion & \\
\hline
\end{tabular}

\section{FURTHER CARE AND ACHIEVEMENT OF THE THERAPEUTIC GOALS}

The goal of treatment is to eliminate all signs and symptoms of depression assessed by PHQ-9, as well as to stabilize the psychological and professional functioning of the person seeking help. Contact with the patient by clinician should take place one week after diagnosis and treatment, and then every 2-4 weeks until remission is achieved (PHQ < 5) or response to treatment (decreased symptoms by $\geq 50 \%$ ). The side effects can preferably be controlled by gradually titrating the dose to achieve a therapeutic effect. Sedation, anxiety, and sexual dysfunction may persist, requiring changes in dosage or even replacement of the drug. Keep in mind that bupropion can cause lethargy, decreased motivation or concentration. Mirtazapine should be effective in insomnia or loss of appetite, not associated with sexual dysfunction, as opposed to SSRIs and SNRIs.

If patient does not respond to the intervention as monotherapy or in combination with psychotherapy within 6 weeks after starting the treatment or only partially responded at week 12, then other treatment options should be considered. In addition, pharmacotherapy should be continued for 4-9 months after symptom remission. The patient should be recommended maintenance therapy for a long period if a history of more than three episodes of depression or two previous episodes in combination with one of the following risk factors: chronic major depressive disorder (severe previous episodes), the presence of residual symptoms, persistent psychosocial early age of manifestation, burdened family history and age over 70 years [1], [2], [3], [13], [20]. Before stopping treatment, the patient should be informed of the potential for recurrence and of the treatment plan if symptoms recur. Discontinuation of antidepressant therapy should last for at least several weeks
[1], [20]. It is equally important to inform the recipient of the completion of appropriate psychotherapeutic interventions before the last session.

\section{REFERRAL TO A SPECIALIST}

Consultation with a psychiatrist is recommended if there is: suspicion of bipolar disorder, comorbid psychiatric disorder (e.g. substance abuse, gambling, anxiety, obsessive compulsive disorder or eating disorder), risk of suicide and / or homicide, psychosis combined with depression signs of improvement when taking drugs prescribed by a primary care physician, despite changes in dosage and replacement of drug classes, significant or prolonged disability, inability to take care and / or family, diagnostic uncertainty [1], [4], [5], [9], [10], [11], [14], [15], [20], [21], [22].

\section{CONCLUSIONS}

Depression is a disorder in which a person for a long time (at least two weeks) feels depressed, loses interest in activities that used to be bring some pleasure and fun. There are different degrees of depression: mild, moderate and severe. It all depends on the number of symptoms and their severity. It is also important to consider whether hypomanic or manic episodes have occurred. Regardless of the type, depression can be chronic (develop over a long period of time) and episodic, with relapses (especially if depression is not treated). Patients with depression have a four times higher risk of suicide than the general population, which worsens their physical health and overall quality of life. In the practice of a general practitioner the prevalence of depression is $5 \%$. Each year, two patients are hospitalized for depression, and one patient commits suicide every other day. There is a need for a clear ability to use various depression screening tools by 
general practitioners. Treatment of depression has to be comprehensive, timely acquired, evidence-based and supported by consultant psychiatrist and licensed mental health specialist as well as psychologist.

\section{REFERENCES}

[1] Lebedyn, Z. (2020). Antidepressants In General Practice And Psychiatry. European Journal of Medical and Health Sciences, 2(3). https://doi.org/10.24018/ejmed.2020.2.3.318.

[2] Petlovanyi, P., \& Tsarkov, A. (2017). Depressive Disorder in Child Psychiatric Practice: A Case Report. Health Press Zambia Bull, 1(5), 9.

[3] Tsarkov, A., \& Petlovanyi, P. Depressive Disorder in Child Psychiatric Practice: A. The Health Press, 9.

[4] Siu, A. L., Bibbins-Domingo, K., Grossman, D. C., Baumann, L. C., Davidson, K. W., Ebell, M., \& Krist, A. H. (2016). Screening for depression in adults: US Preventive Services Task Force recommendation statement. Jama, 315(4), 380-387.

[5] Anatolii, T., Patrick, M., \& Petro, P. (2020). Uncommon presentation: Folie à deux (Case study). World Journal of Advanced Research and Reviews, 6(3), 043-049.

[6] Ben-Porath, Y. S., Butcher, J. N., \& Graham, J. R. (1991). Contribution of the MMPI-2 content scales to the differential diagnosis of schizophrenia and major depression. Psychological Assessment: A Journal of Consulting and Clinical Psychology, 3(4), 634.

[7] Tsarkov, A., \& Petlovanyi, P. (2016). Bipolar Disorder in Child Psychiatric Practice: A Case Report. Medical Journal of Zambia, 43(1), 41-46.

[8] Tsarkov, A., \& Petlovanyi, P. (2016). Bipolar disorder in child psychiatric practice.

[9] Katz, S. J., Kessler, R. C., Lin, E., \& Wells, K. B. (1998). Medication management of depression in the United States and Ontario. Journal of General Internal Medicine, 13(2), 77-85.

[10] Petlovanyi, P., \& Tsarkov, A. Child Schizophrenia: Theory and Practice.

[11] Tsarkov, A., \& Petlovanyi, P. (2019). Neuropsychiatric Aspects of a Common Problem: Stroke. European Journal of Medical and Health Sciences, 1(3). https://doi.org/10.24018/ejmed.2019.1.3.64.

[12] Petlovanyi, P., \& Tsarkov, A. (2020). Child Schizophrenia: Theory and Practice. European Journal of Medical and Health Sciences, 2(1). https://doi.org/10.24018/ejmed.2020.2.1.160.

[13] Janssen, N., Huibers, M. J., Lucassen, P., Voshaar, R. O., van Marwijk, H., Bosmans, J., ... \& Hendriks, G. J. (2017). Behavioural activation by mental health nurses for late-life depression in primary care: a randomized controlled trial. BMC psychiatry, 17(1), 1-11.

[14] Parker, G., \& Fletcher, K. (2007). Treating depression with the evidence-based psychotherapies: a critique of the evidence. Acta Psychiatrica Scandinavica, 115(5), 352-359.

[15] Pagnin, D., de Queiroz, V., Pini, S., \& Cassano, G. B. (2004). Efficacy of ECT in depression: a meta-analytic review. The journal of ECT, 20(1), 13-20.

[16] Tsarkov, A., \& Petlovanyi, P. (2017). Omega-3 Fatty Acids as an Alternative Treatment for Children with Attention Deficit Hyperactivity Disorder. Imperial Journal of Interdisciplinary Research (IJIR), 3, 1378-1380.

[17] Tsarkov, A., \& Petlovanyi, P. The Role of Lamotrigine in the Treatment of Bipolar Depression.

[18] O’Neil, A., Berk, M., Venugopal, K., Kim, S. W., Williams, L. J., \& Jacka, F. N. (2014). The association between poor dental health and depression: findings from a large-scale, population-based study (the NHANES study). General hospital psychiatry, 36(3), 266-270.

[19] Phiri, C., Tsarkov, A., Petlovanyi, P., \& Lingenda, G. Factors Contributing To Oral Diseases and Treatment Needs amongst Mental Patients at Chainama Hills College Hospital, Lusaka, Zambia.

[20] Lebedyn, Z. (2019). The Use of Antidepressants by General Practitioners and Psychiatrists (Personal Experience).

[21] Tsarkov, A., \& Petlovanyi, P. (2017). Pathological Gambling: The Old Problem of the Modern World. Imperial Journal of Interdisciplinary Research, 3(8), 216-221.

[22] Kennedy, S. H., Lam, R. W., McIntyre, R. S., Tourjman, S. V., Bhat, V., Blier, P., \& McInerney, S. J. (2016). Canadian Network for Mood and Anxiety Treatments (CANMAT) 2016 clinical guidelines for the management of adults with major depressive disorder: section 3 . Pharmacological treatments. The Canadian Journal of Psychiatry, 61(9), 540-560. 